\title{
The longitudinal relationship between early inhibitory control skills and emergent literacy in preschool children
}

\author{
Elena Gandolfi ${ }^{1}$ (D) - Laura Traverso ${ }^{1}$ - Mirella Zanobini ${ }^{1} \cdot$ Maria Carmen Usai $^{1}$. \\ Paola Viterbori ${ }^{1}$
}

Accepted: 26 January 2021 / Published online: 10 February 2021

(c) The Author(s) 2021

\begin{abstract}
This study analyses the longitudinal relationship between early inhibitory control skills and subsequent emergent literacy. At Time 1, a sample of 50 typically monolingual Italian toddlers aged 28 to 36 months in their last year of day-care was assessed on expressive vocabulary and two inhibitory control measures, tapping specifically response inhibition and interference suppression. At Time 2, during the preschool years, children aged 49 to 72 months were re-assessed on a battery of emergent literacy tasks including three phonological awareness tasks and an orthographic knowledge task. The results of the hierarchical linear regression analyses suggest that interference suppression evaluated at Time 1 is a key process in the acquisition and construction of both phonological awareness and early orthographic knowledge, even when children's early expressive vocabulary was included in the analyses. Unlike previous studies, the present study included very young children, thus allowing us to explore the developmental antecedents of two important precursors of reading and writing abilities.
\end{abstract}

Keywords Inhibitory control · Emergent literacy · Interference suppression · Phonologicalawareness · Orthographic knowledge

Although literature has broadly recognized the critical role of the executive functions (EF) in explaining the individual differences in pre-academic skills (Becker, Miao, Duncan, \& McClelland, 2014; Kegel \& Bus, 2014), relatively little is known about very early precursors of both math and literacy abilities before entering school (Shaul \& Schwartz, 2014). In particular, there is a lack of knowledge about the role of early inhibitory control skills, that are the first executive processes that develop (Gandolfi, Viterbori, Traverso, \& Usai, 2014), in explaining subsequent emergent literacy precursors. The current study aims to investigate the longitudinal relationship

Elena Gandolfi

elena.gandolfi@unige.it

1 Department of Education Sciences, University of Genoa, C.so A. Podestà 2, 16128 Genoa, Italy 
between early inhibitory control skills, assessed in typically developing children in the third year of life, and subsequent emergent literacy, assessed between the ages of 4 and 6. In particular, it explores whether early expressive vocabulary and inhibitory control abilities, namely response inhibition and interference suppression, are longitudinally associated with phonological awareness and early orthographic knowledge skills before the beginning of primary school. To our knowledge, no studies have investigated the role of different inhibitory control processes, assessed in children within age three, in predicting subsequent emergent literacy abilities.

\section{Inhibitory control in early childhood}

Inhibitory control is a central component of EF that is a set of interrelated cognitive processes that regulate one's thoughts and behaviors (Miyake \& Friedman, 2012). Regarding EF developmental paths, previous studies agreed in considering a single undifferentiated EF factor the most appropriate to describe the latent structure in young children (Hughes, Ensor, Wilson, \& Graham, 2009; Wiebe et al., 2011). The two factor model seemed to show the best fit in preschool and early school years (Usai, Viterbori, Traverso, \& De Franchis, 2014), whereas the tripartite organization, including inhibition, updating and shifting, is not attained before middle childhood (Lehto, Juujärvi, Kooistra, \& Pulkkinen, 2003).

Inhibitory control is the first EF component that develops (see Diamond, 2013); it emerges in the first year of life and develops throughout infancy and childhood, allowing children to progressively control their behavior. Recently, inhibitory control has been conceptualized as a set of sub-functions rather than a unique individual ability, already in early preschool years (Traverso, Viterbori, Malagoli, \& Usai, 2020). Nevertheless, research on the structure and the latent organization of inhibitory control in childhood provided mixed results (Petersen, Hoyniak, McQuillan, Bates, \& Staples, 2016). Several studies have identified in toddlers and preschoolage children two separate inhibitory components, namely delay inhibition and conflict inhibition (Carlson \& Moses, 2001; Diamond, Prevor, Callender, \& Druin, 1997). The former is defined as the ability to suppress or delay a prepotent response (Kochanska, Murray, \& Harlan, 2000), whereas the latter refers to the ability to inhibit an automatic response and to execute a novel, conflicting response (MartinRhee \& Bialystok, 2008). Similarly, Gandolfi et al. (2014) have identified two inhibitory control components that emerge by approximately three years of age, response inhibition and interference suppression. Response inhibition refers to the ability to suppress a dominant but inappropriate response in order to display a weaker but more adequate one. Interference suppression develops later than response inhibition and involves the ability to suppress interfering information and to select the piece of information one has to respond to. In particular, according to Bunge, Dudukovic, Thomason, Vaidya and Gabrieli (2002), in response inhibition tasks children have to deal with the conflict between two response options to the same stimulus (e.g., in the Circle Drawing task children must control their impulsive motor response to slow down their performance when they are tracing the circle), whereas in interference suppression tasks children must filter out information by managing the conflict 
between several misleading and interfering features of a complex stimulus (e.g., in the Fish task children must respond to a central target flanked by interfering stimuli that need to be suppressed in order to accomplish the task).

The separability of the inhibitory control construct into response inhibition and interference suppression components have been recently found also in toddlers (Gandolfi \& Viterbori, 2020; but Usai, Viterbori, Gandolfi \& Zanobini, 2020) and in preschool children (Traverso, Fontana, Usai, \& Passolunghi, 2018). However, this type of organization is not universally accepted (Joyce et al., 2016). Therefore, given the sparse literature about the organization of inhibitory skills in young children, further research is needed to reveal a general developmental path.

\section{Emergent literacy}

Reading and writing abilities require the coordination of a number of component skills that vary in their cognitive complexity (Purpura, Schmitt, \& Ganley, 2017) and develop over many years before reading and writing themselves emerge. Among the wide range of predictors of literacy, the phonological processing skills, such as rapid automatized naming, phonological short-term memory and phonological awareness, are the most studied (Castles \& Coltheart, 2004; Peterson et al., 2018). Nevertheless, there is further evidence that reading and writing skills are affected also by other abilities, such as orthographic knowledge (Conrad, Harris, \& Williams, 2013; Shaul \& Schwartz, 2014).

Concerning the phonological processing precursors, the rapid automatized naming, that is assessed by tasks that require to quickly name a series of non-alphabetic stimuli (e.g., pictured familiar objects), involves several cognitive and linguistic processes, such as attention to the stimuli, visual discrimination, integration of visual information with stored orthographic and phonological representation, lexical access and retrieval, and organization of articulatory input (Wolf \& Bowers, 1999). Although rapid automatized naming has been broadly considered as the best predictor of reading (Kirby, Desrochers, Roth, \& Lai, 2008), the meta-analysis of Araújo, Reis, Petersson, and Faísca (2015) revealed mixed results across the studies caused mainly by differences in the assessment methods of rapid automatized naming, participants' reading performance and age ranges. More recently, some authors also found a bidirectional relationship between literacy and oral language skills, showing an effect of earlier literacy on later rapid automatized naming, especially in the first phase of literacy development (Peterson et al., 2018).

Phonological short-term memory has also been found to be related with reading (de Jong \& Van der Leij, 1999) and, to a lesser extent, with spelling skills (Plaza \& Cohen, 2007). Phonological short-term memory allows to briefly maintain verbal information to conscious awareness and plays a critical role in decoding development because it enables to retain the order of the phonemes until these are blended into a word for pronunciation (Binamè \& Poncelet, 2016).

Phonological awareness refers to the ability to attend to, isolate, and manipulate the sound structure of oral language (Wagner, Torgesen, Rashotte, \& Pearson, 1999). More specifically, it can be considered "the ability to detect, 
manipulate, or analyze the auditory aspects of spoken language (including the ability to distinguish segment words, syllables, or phonemes), independent of meaning" (Lonigan \& Shanahan, 2009, p. 3). Research demonstrates a progression in the order in which children acquire phonological awareness, such that awareness of larger speech segments (words, syllables) precedes awareness of smaller segments (onset-rimes, phonemes) (Goswami, 1999; Schuele \& Boudreau, 2008). Knowledge about syllables, onsets and rhymes had been found in pre-reading children in many languages, whereas phoneme awareness seems largely a consequence of reading instructions (Goswami \& Bryant, 2016).

A great number of studies have demonstrated that phonological awareness is a strong predictor of reading and writing across languages, regardless of their orthographic consistency (Castles \& Coltheart, 2004; Lonigan, Burgess, \& Anthony, 2000). Lonigan et al. (2000) demonstrated that phonological awareness, compared to many other predictors, was the most stable and robust indicator of subsequent reading in children who were followed from late preschool into kindergarten and first grade. Regarding writing, Caravolas, Hulme, and Snowling (2001) found that the awareness of phonemic units correlated even more strongly to spelling than reading.

Early orthographic knowledge refers to preschool children's capacity to graphically represent spoken language before they receive formal instruction in writing and spelling. This ability typically begins when children represent language by means of drawing or scribbling and gradually progresses to more conventional writing, using letters to represent sounds that form words (Milburn et al., 2017). It can be assessed through various tasks that explore how young children map language into print, such as letter-sound recognition, letter-name and letter-sound production, children's name writing and invented spelling, which refers to the attempts made by preliterate children to represent words in print before receiving any formal instruction.

While phonological awareness is generally recognized to contribute to both reading and writing (Caravolas et al., 2001), the contribution of orthographic knowledge is less understood (Castles \& Nation, 2006). Several studies showed that orthographic knowledge contributed unique variance to reading ability, also when phonological awareness was concurrently considered. Nevertheless, few studies specifically address the contribution of orthographic knowledge to spelling skills especially in preschool children (Caravolas et al., 2001; Ouellette \& Senechal, 2008). Conrad et al. (2013) found in school age children that orthographic knowledge made a separate and unique contribution to reading and spelling concurrently considered, over and above the contribution of phonological awareness skills.

As evidenced, phonological awareness and early orthographic knowledge can be assessed before children are formally instructed to read and write. In fact, as suggested by many authors, in literate societies young children are largely exposed to a variety of literacy experiences and accumulate knowledge about the written representation of oral language before primary school (Hooper et al., 2020; Leseman \& de Jong, 1998). 


\section{Vocabulary and emergent literacy}

Many studies indicate that oral language and reading abilities are closely associated (Lee, 2008; Poe, Burchinal, \& Roberts, 2004) and a variety of oral language abilities such as vocabulary, syntax and oral narrative skills have been found to be critical for emergent literacy, particularly for the development of reading skills (e.g., Dickinson, McCabe, Anastasopoulos, Peisner-Feinberg, \& Poe, 2003; Whitehurst \& Lonigan, 2001). As regards the relationship between oral language and early literacy, many studies have found significant concurrent linkages between preschool children's vocabulary skills and phonological awareness (Lonigan et al., 2009; Suggate, Schaughency, McAnally, \& Reese, 2018).

It has been broadly recognized that in very early stages of language development, lexical acquisition is affected by productive phonological skills (Fasolo, Majorano, \& D'Odorico, 2008; Zanobini, Viterbori, \& Saraceno, 2012), in fact children's first words are found to be composed of phonemes that are already present in their bubbling (Goswami, 2000). However, several studies emphasized the reciprocal relationship between phonological and lexical skills, that is especially evident in older children (Curtin \& Zamuner, 2014; Storkel \& Morrisette, 2002; Viterbori, Zanobini \& Cozzani, 2018).

Lonigan (2007), for example, reporting the results of an intervention study addressed to preschool children, found that vocabulary training resulted in a significant growth in phonological awareness, whereas, conversely, a phonological awareness intervention had no effect on vocabulary development. These results support the hypothesis that vocabulary development sets the stage for phonological awareness, as suggested for example by the Lexical Restructuring Model (LRM; Metsala \& Walley, 1998; Walley, Metsala, \& Garlock, 2003). According to this model, in early childhood, given the small number of words known by children, fine-grained representations are not necessary to distinguish different words; nevertheless, as children develop larger vocabularies, words with similar phonology increase and the lexicon must be represented more segmentally to allow for differentiation among words.

Similarly, Sosa and Stoel-Gammon (2012) found in typical toddlers that lexical factors influenced some phonological variables, suggesting that between the ages of 2 and 2;5, children's word production depends on whole word lexical representation rather than on categorical phonological representation. As a result, phonological representations become more segmental as the lexicon grows. According to the Lexical Restructuring Model, these results might suggest that in toddlers and preschool children phonological and meta-phonological skills could be particularly involved when the lexical repertoire becomes broader enabling children to distinguish words with similar sounds.

The role of vocabulary in orthographic knowledge is less clear. Some studies have reported moderate correlations between the two (Otaiba et al., 2010; Kim et al., 2011); nevertheless, Ouellette and Sénéchal (2008) found that vocabulary was not related to children's invented spelling once phonological awareness was taken into consideration in a sample of kindergartners. Differently, Kim, Otaiba, 
Puranik, Folsom and Gruelich (2014), using structural equation modeling, showed that receptive vocabulary was associated to both word reading and word spelling after accounting for phonological awareness, alphabet knowledge and letter writing automaticity.

\section{Inhibitory control development and emergent literacy}

Generally, inhibitory control skills, assessed in the preschool years, were found to be associated to or predictive of early achievement, particularly emerging math skills (Fuhs \& McNeil, 2013; McClelland et al., 2007). As regards early literacy, several studies have found a relationship between various emergent literacy skills and composite or individual measures of inhibitory control, which was mainly assessed with response inhibition tasks (Allan \& Lonigan, 2011; Becker et al., 2014). One of the most widely used inhibitory control task in this research field is Head-ToesKnees-Shoulders task (HTKS, McClelland et al., 2007) that is considered an aggregate measure of behavioral self-regulation because requires to inhibit an automatic behavioral response to perform a subdominant response. McClelland and colleagues (2014) found in kindergarteners that the HTKS task was the most consistent predictor of early literacy, particularly of developing decoding skills (assessed with letter-word identification). Similarly, Montoya et al. (2019), in examining differential contribution of verbal and visual short-term memory and inhibitory control on early achievement in preschool-aged children, showed that the performance on HTKS task was strongly associated with early decoding.

As specifically regards phonological awareness outcome, measured with rhyming, blending, segmentation, elision, or substitution tasks (see Purpura et al., 2017; Zhang et al., 2017), several studies demonstrated that the inhibitory control was a significant predictor in preschoolers (Allan \& Lonigan, 2011) even in languageminority children (Lonigan, Lerner, Goodrich, Farrington, \& Allan, 2016), with some exceptions such as the study by Purpura, et al. (2017) in which inhibitory control was not predictive of phonological awareness. In this regard, Zhang et al. (2017) found that inhibitory control assessed at the beginning of the school year was significantly associated with the amount of growth in emergent literacy, such as letter naming and letter-sound skills across the year; nevertheless no relation between inhibitory control and the growth of phonological awareness measures were found.

As regards early orthographic skills, only a few studies have analyzed the role of inhibitory control in emergent spelling abilities using writing tasks, such as word dictation (Kegel \& Bus, 2014), and invented spelling (Zhang et al., 2017). Kegel and Bus (2014) found that in preschoolers emergent spelling was related to a Stroop-like task, which requires to resolve a conflict between competing responses. Similarly, Shaul and Schwartz (2014) showed that a composite measure of the HTKS and the Statue test, which taps inhibition of prepotent motor response, significantly contributed to orthographic knowledge, also after controlling for naming speed and vocabulary measures.

In summary, these results suggest a relationship between some emergent literacy skills, particularly phonological awareness and orthographic knowledge, and 
inhibitory control assessed mainly by response inhibition measures. To our knowledge, no studies have investigated the concurrent contribution of different inhibitory control components to emergent literacy. An exception is represented by a recent intervention study that found that a preschool training, that proved to be effective on interference suppression, resulted in an improvement in orthographic knowledge (Traverso, Viterbori, \& Usai, 2019). These findings suggest that the ability to select the right piece of information and resist the interference of irrelevant stimuli could assist children in their attempts at translating spoken language into print.

\section{The present study}

Given the strong predictive and causal relations between emergent literacy abilities and later reading and writing skills, it is important to identify the developmental precursors of emergent literacy itself. Specifically, the present longitudinal study is focused on the role of early inhibitory control skills in the development of both phonological awareness and early orthographic knowledge. Unlike previous studies, both forms of inhibitory control-response inhibition and interference suppression-were considered in the present study; in addition, inhibitory control skills were assessed at a very early stage, between the ages of 28 to 36 months, whereas phonological awareness and early orthographic knowledge were evaluated between 4 and 6 years of age.

Given the role that oral language skills play in the development of reading and writing precursors and abilities, vocabulary was considered as a predictor in addition to inhibitory control skills. Based on previous literature we hypothesize that vocabulary shows significant correlations with emergent literacy, mainly with phonological awareness (see Lonigan et al., 2009). As regards the role of inhibitory control skills, it is difficult to make hypotheses, since previous studies did not distinguish clearly between the two types of inhibition accounting for emergent literacy. Nevertheless, we suggest that it is not only response inhibition that may assist children in the development of emergent literacy. Interference suppression, which requires the ability to address conflict from misleading features of the task, may play a special role as well (see Traverso et al., 2019). In fact, in order to isolate and categorize the sound structure of oral language, children have to focus on the similarities/differences of sounds and syllables, managing the interference from the meaning of the words. Similarly, early attempts to represent words in print require children to match sounds or syllables with written words resisting conflict from similar sounds, syllables and letters.

\section{Methods}

\section{Participants}

A total of 52 typically developing children between the ages of 28 and 36 months $(M=30.19$ months; $\mathrm{SD}=2.35 ; 52 \%$ females) from three different public day-care 
centers were included in the first assessment of the longitudinal study (Time 1). Participants were recruited at five public day-care centres serving families with a range of socioeconomic backgrounds in a large town in North-western Italy. To be eligible for the study, the children had to meet the following criteria: to be monolingual with Italian as their main language, and to have no documented neurological, psychiatric o developmental disorder. Due to their poor comprehension of Italian because of their major exposure to languages other than Italian at home, two of the 52 children who originally took part in the study were excluded from the statistical analyses. The final sample included 50 children between the ages of 28 and 36 months ( $M=30.18$ months; $\mathrm{SD}=2.38 ; 54 \%$ females).

The current research is part of a wider study that aimed to explore inhibitory control and language in day-care children and that foresaw an extended period of data collection. Given that Time 1 data collection on the entire sample was carried in two school years, Time 2 assessment enrolled a subsample of 30 children between the ages of 49 and 59 months $(M=53.87$ months; $S D=3.63 ; 60 \%$ females $)$ tested at Time 1 two years before, and a subsample of 20 children between the ages of 60 and 71 months $(M=64.15$ months; $\mathrm{SD}=3.57 ; 45 \%$ females $)$ tested at Time 1 three years before.

All the children who participated at the Time 2 assessment were recruited at three public preschools located in different areas of the same town. The annual report provided by the preschools showed that the school's catchment area is represented by families from different income levels and social background. Parents completed an educational background checklist; mothers' education ranged from 5 to 21 years $(M=15.56, \mathrm{SD}=3.74)$; specifically, $6 \%$ of the mothers had completed middle school education ( 8 years), $44 \%$ of the mothers had also completed high school education (13 years), and $50 \%$ of the mothers also had a university degree. At both Time 1 and Time 2 assessments, the families were informed of the aims and the method of the study and the parents who allowed their children to participate filled in the parental informed consent form. This study was approved by the local Department Ethical Committee and was carried out in accordance with the recommendations of the Ethical Code of the Italian National Council of Psychologists and of the Ethical guidelines of the Italian Association of Psychology.

\section{Procedure}

At Time 1 parents completed the Italian version of the parent-report questionnaire MacArthur-Bates Communicative Development Inventory (CDI, Fenson, Dale, Reznick, Thal, Bates, Hartung, Pethick, \& Reilly, 1993) over a period of 10 days and, at the same time, their children were individually administered two inhibitory control tasks in a quiet room of their day-care centre. The assessments were carried out by the researchers in a 20-min session. At Time 2 children were administered a battery of four emergent literacy tasks assessing phonological awareness and early orthographic knowledge skills. At Time 2 children were individually assessed by the researchers in a quiet room of their pre-school in a single session lasting approximately $30 \mathrm{~min}$. 


\section{Time 1 measures}

\section{Language checklist}

The Italian version of the MacArthur-Bates Communicative Development Inventory (CDI, Fenson et al., 1993; PVB-Il primo vocabolario del bambino; Caselli, Pasqualetti, \& Stefanini, 2007) was completed by the parents. We used the "Words and Sentences" short form which is suitable for children aged 18 to 30 months and includes a 100-word vocabulary checklist and two subscales to evaluate early grammatical skills and qualitative aspects of communication. For the present study we considered the vocabulary checklist which includes a list of 100 words organized into different categories, e.g., social words (10 onomatopoeia words, routine words and people's names), nouns (46 words about animals, vehicles, toys, food and drink, clothing, body parts, small household items, furniture and rooms, outside things, and places to go), predicates ( 21 words about verbs, adjectives, etc.), adverbs (5 words), modal verbs (4 words) and function words (14 words about pronouns, question words, prepositions and locations, quantifiers and articles, and connecting words). It has been demonstrated that the CDI has adequate psychometric characteristics (see Fenson, Marchman, Thal, Dale, \& Reznick, 2007; Law \& Roy, 2008); concerning concurrent validity, moderate to strong correlations between parental reports and spontaneous expressive vocabulary were found (Ring \& Fenson, 2000). Regarding the Italian version of the "Words and Sentences" short form used for the purpose of this study, the concurrent validity was demonstrated in relation to an Italian standardized task testing lexical comprehension and production which was found to be significantly correlated with the CDI expressive vocabulary size $(r=0.526$, Bello, Giannantoni, Pettinati, Stefanini, \& Caselli, 2012). In the present study the score represents the expressive vocabulary that is the number of lexical items produced by the child (expected range: $0-100)$.

\section{Inhibitory control measures}

The following tasks were employed to assess two different inhibitory control abilities, such as the ability to inhibit a dominant response (response inhibition) and the ability to manage the interference among conflicting characteristics of the stimuli (interference suppression).

The Circle Drawing task is a standardized task (Usai, Traverso, Gandolfi, \& Viterbori, 2017) that was used to assess the ability to inhibit an on-going response. The child is required to move two different puppets on a17-cm diameter circle drawn on a cardboard square. In the first neutral phase of the task, the child is instructed to move a boy-puppet along the circle, whereas in the second phase the child is required to move a turtle-puppet along the circle as slowly as he/she can, like a turtle. The score is calculated as the proportion of the slowdown to the total time using the following formula: $T 2-T 1 / T 1+T 2$, where $T 1$ is the amount of time needed to move the boy-puppet along the circle and $T 2$ is the amount of time needed to move the turtle-puppet along the circle. This task has been used to assess inhibition in both adults and children (Geurts, Vert, Oosterlaan, Roeyers, \& Sergeant, 2005; Usai et al., 
2014). Concerning validity, the Circle Drawing task has been shown as a significant predictor of inhibition latent factor in preschool children (Usai et al., 2014); the concurrent validity, that was calculated by correlating the Circle Drawing task scores with widespread response inhibition measures, has been demonstrated for many of them, such as the Matching familiar figure task $(r=.326$, Traverso, Mantini, Usai, $\&$ Viterbori, 2016). The test-retest reliability coefficient was calculated on a sample of 43 five-year-olds, who had been assessed twice in a previous study by Traverso, Viterbori, and Usai (2015). The Pearson correlation coefficient was 0.57.

The Fish task is a standardized task (Usai et al., 2017) and it is an adaptation of the well-known paradigm used to evaluate the ability to inhibit visual interference (Eriksen \& Eriksen, 1974). We used the 24-to 36-month standardized paper version of the task (Usai et al., 2017) in which each child is required to indicate in which direction a blue, centrally located target fish is oriented, by pointing to the fish food located on the left or on the right side of the cardboard table $(297 \mathrm{~mm} \times 210 \mathrm{~mm})$. To do this, the child must inhibit the interference of four same-sized, green fishes facing in different directions (two on the left side and two on the right side of the target fish). There are 14 trials: 2 training trials, 6 congruent trials with the target and the interfering stimuli oriented in the same direction, and 6 incongruent trials with the target oriented in the opposite direction of the interfering stimuli. Congruent and incongruent trials are randomly presented. The flanker paradigm has been widely used to assess interference suppression both in adults (Friedman \& Miyake, 2004) and children (Bossert, Kaurin, Preckel, \& Frings, 2014; Gandolfi et al., 2014). The validity of the task has been confirmed in previous studies that revealed the Fish task as a significant predictor of the interference suppression dimension (Gandolfi et al., 2014; Traverso, et al., 2018). The accuracy in the incongruent trials was scored (expected range 0-6) following the procedure of the standardized version of the task (Usai et al., 2017). The Cronbach's alpha was 0.64.

\section{Time 2 measures}

\section{The emergent literacy battery}

We administered three phonological awareness subtests of the CMF (Marotta, Ronchetti, Tresciani, \& Vicari, 2008), which is a standardized battery for the assessment of meta-phonological skills in preschool children. This battery was standardized on an Italian monolingual sample of 1336 children from $4 ; 11$ to $11 ; 10$. The test-retest reliability Spearman coefficient calculated on a randomized sample of 15 six-yearolds ranged from 0.90 to 0.97 for the three subtests considered for the current study.

The Syllable blending task measures children's blending abilities. Each child is required to blend two, three and four orally presented syllables into a complete word. The instructions are as follows: "I will tell you some pieces of a word and you must combine them to form a word". For example: "What do you get when you say SO-LE together?". There is one practice word-item (a two-syllable word) and a total of 14 test trials subdivided in four two-syllable words, six three-syllable words and four four-syllable words. The items were presented in order of difficulty, with 
two-syllable items administered before the three- and four-syllable words. The score is the number of words correctly blended by the children (expected range $0-14$ ). The Cronbach's alpha was 0.62 .

In the Rhyme detection task the child is required to identify the word with the same last syllable as the word produced by the examiner. The child is presented with a cardboard table representing four pictures, one picture corresponds to the target word, another picture corresponds to the word that ends with the same syllable as the target, and the other two pictures are the distractors. Starting from the target, the examiner points to and names all the pictures, then he/she asks the child to point to the picture corresponding to the word that ends with the same sound as the previously named target word. The instruction is: "What is the word that sounds like and rhymes with PACCO? Is it TORO? Is it SACCO? Is it CALZA?". The task includes 15 word-items randomly presented; before starting the child is provided with a training item. During the test phase the examiner repeats the instructions every time, but he/she doesn't give any feedback to the child. The score is the number of words correctly identified by the children (expected range 0-15). The Cronbach's alpha was 0.90 .

The Minimal pairs task assesses the ability to detect the phonological features of the words. A minimal pair is a pair of words that differ in a single phoneme. The child is orally presented with minimal pairs of words and he/she is required to judge if they are exactly the same words. The instruction is: "Now I'll tell you two words, and you tell me if they are exactly the same word or if they are two different words, for example, I say: $\underline{P}$ OLLO $\underline{B}$ OLLO. Did I say the same word, or did I say two different words?". There are two training trials and a total of 30 test trials subdivided into 15 words and 15 non-words (expected range 0-30). The Cronbach's alpha was 0.86 .

The Early orthographic knowledge task is an experimental task based on Ferreiro and Teberosky's (1982) model of spelling acquisition. The child is required to write the name of four different pictures (e. g., "cane"/“dog", "sole"/“sun", "tavolo"/"table", "elefante"/"elephant") represented on a cardboard table. There are two two-syllable words ("ca-ne", "so-le"), one three-syllable word ("ta-vo-lo") and one four-syllable word ("e-le-fan-te"). All the words except "elefante" are simple and include the $\mathrm{C}-\mathrm{V}-\mathrm{C}-\mathrm{V}$ sequence. Before the writing performance, the examiner asks the child to name the pictures one by one, then he/she provides the instruction: "How could you write the word "dog"? How could you write the word "sun"? etc." A score ranging from 0 to 5 was assigned to each of the four figures: 0 indicates writing by means of drawing or scribbling (scribble stage), 1 indicates writing by using random letters: in this stage the child uses random letters without any link with the word's signifier, for example, the letters E-O-A-C-R stand for the Italian word TAVOLO (pre-conventional or pre-syllabic stage); 2 indicates writing by reproducing one letter for each syllable without any conventional correspondence between the letters and the phonemes, for example, the letters O-E-A stand for the three-syllable Italian word TA-VO-LO (pre-conventional syllabic stage); 3 indicates writing by reproducing one letter for each syllable and following the conventional grapheme/phoneme correspondence rule: for example, $\mathrm{T}-\mathrm{V}-\mathrm{L}$ stand for the three-syllable Italian word TA-VO-LO (conventional syllabic stage); 4 indicates 
writing by reproducing more letters for one whole syllable, for example, TA-V-LO stands for the three-syllable Italian word TA-VO-LO (syllabic-alphabetic stage); 5 indicates writing by reproducing each letter according with the sound it represents, following the grapheme/phoneme correspondence rule (alphabetic stage). The final score was given by the mean of the scores obtained in each of the four pictures. Two judges coded the children's performance independently. The correlations between the two judges indicated adequate coding reliability $(r=0.834 ., p<0.001)$.

\section{Statistical analyses}

Descriptive statistics (i.e., means, standard deviations, skewness, and kurtosis) and zero-order (Pearson) and partial correlations controlling for age between inhibitory control and expressive vocabulary at Time 1 were calculated. Descriptive statistics (i.e., means, standard deviations, score ranges, skewness, and kurtosis) for Time 2 emergent literacy measures (syllable blending, rhyme detection, minimal pairs, early orthographic knowledge) for both age groups were provided. To reduce data, a phonological awareness composite score was calculated as the mean of the $\mathrm{z}$ scores for the syllable blending, the rhyme detection and the minimal pair scores. Zeroorder (Pearson) correlations between Time 1 and Time 2 measures (the phonological awareness composite score and early orthographic knowledge score) were performed for both subsamples.

To investigate the contribution of expressive vocabulary and inhibitory control abilities on both phonological awareness and early orthographic knowledge, separate hierarchical linear regression analyses (enter method) were conducted on the whole sample (4-5-year age group along with 5-6-year age group). Time 2 emergent literacy measures (phonological awareness score and early orthographic knowledge), were considered as dependent variables in separate regression models and the independent variables were included in four blocks of analysis. Time 2 age group was included in the first block, mother's education level was included in the second block, vocabulary and both the inhibitory control measures evaluated at Time 1 were included in the third block and fourth block, respectively. Time 2 age group was included as a categorical (dummy) variable, where the value of 0 was assigned to the 4-5 year subsample and the value of 1 was assigned to the 5-6 year subsample. All necessary assumptions of a regression analysis were met, and the Inspection of Variance Inflation Factors and Tolerance values, as well as the Condition Index and the Durbin-Watson Index indicated that there were no collinearity problems.

\section{Results}

Descriptive statistics for Time 1 measures are reported in Table 1 . With respect to inhibitory control measures, $84 \%$ of the children completed the Fish task and $94 \%$ completed the Circle Drawing task. No missing value was found for the expressive vocabulary measure. 
Table 1 Descriptive statistics for expressive vocabulary and inhibitory control measures at Time 1

\begin{tabular}{lllllll}
\hline & $\mathrm{N}$ & Min-Max & $\mathrm{M}$ & $\mathrm{SD}$ & Skewness (S.E.) & Kurtosis (S.E.) \\
\hline Vocabulary & 50 & $2-100$ & 53.7 & 27.07 & $-.01(.34)$ & $-.93(.66)$ \\
Circle & 47 & $-0.72-0.64$ & 0.11 & 0.28 & $-.59(.34)$ & $.46(.68)$ \\
Fish & 42 & $0-6$ & 3.29 & 1.72 & $-.41(.37)$ & $-.61(.71)$ \\
\hline
\end{tabular}

Vocabulary, Expressive vocabulary; Circle, Circle Drawing task; Fish, Fish task

Zero-order (Pearson) and partial correlations adjusted for age among the Time 1 measures showed that the inhibitory control measures correlated with one another $(r=0.382, p<0.012)$ and this association remained significant even after controlling for age $(r=0.335, p<0.032)$. Only the interference suppression task (the Fish task) correlated with the expressive vocabulary measure $(r=0.478, p<0.001)$.) when age was partialled out $(r=0.454, p<0.003)$. Differently, the response inhibition task (the Circle Drawing task) correlated moderately with expressive vocabulary $(r=0.307$, $p<0.048)$ and this association did not remain significant after controlling for age $(r=0.246, p<0.122)$.

Descriptive statistics for Time 2 measures and zero order correlation analyses among Time 1 and Time 2 measures were conducted for both age groups (Tables 2 and 3). Considering language at Time 1, it can be noted that in the 4-5 year sample expressive vocabulary was significantly associated with the phonological awareness score (and with the minimal pairs measure), whereas in the 5-6 year sample expressive vocabulary was significantly associated with the early orthographic knowledge measure (and with the rhyme detection score).

As regards inhibitory control measures at Time 1, the correlation analyses showed similar association patterns for both age groups: the early interference suppression task was significantly associated with most of the emergent literacy outcomes, while the response inhibition task was not. Particularly, at 4-5 years the Fish task correlated highly with the phonological awareness score, the minimal pairs, the rhyme detection and the early orthographic knowledge measures; similarly, at 5-6 years the Fish task correlated moderately with the phonological awareness score, the rhyme detection and the early orthographic knowledge measures. No association between the Circle Drawing task and the emergent literacy measures was found. Mother's education significantly correlated with all the emergent literacy measures (except for rhyme detection) in the 4-5 year age group and in the 5-6 year group correlated only with the rhyme detection measure.

To determine whether Time 1 early expressive vocabulary and inhibitory control measures explained the amount of variance in both the phonological awareness score and the early orthographic knowledge measure at Time 2, a series of hierarchical linear regression analyses (enter method) were performed. Due to the limited number of children in both the subsamples, we conducted the regression analyses on the whole sample (4-5 year age group along with 5-6 year age group). The independent variables were included in four blocks of analysis: Time 2 age group was included in the first block, mother's education level (years of education) was 


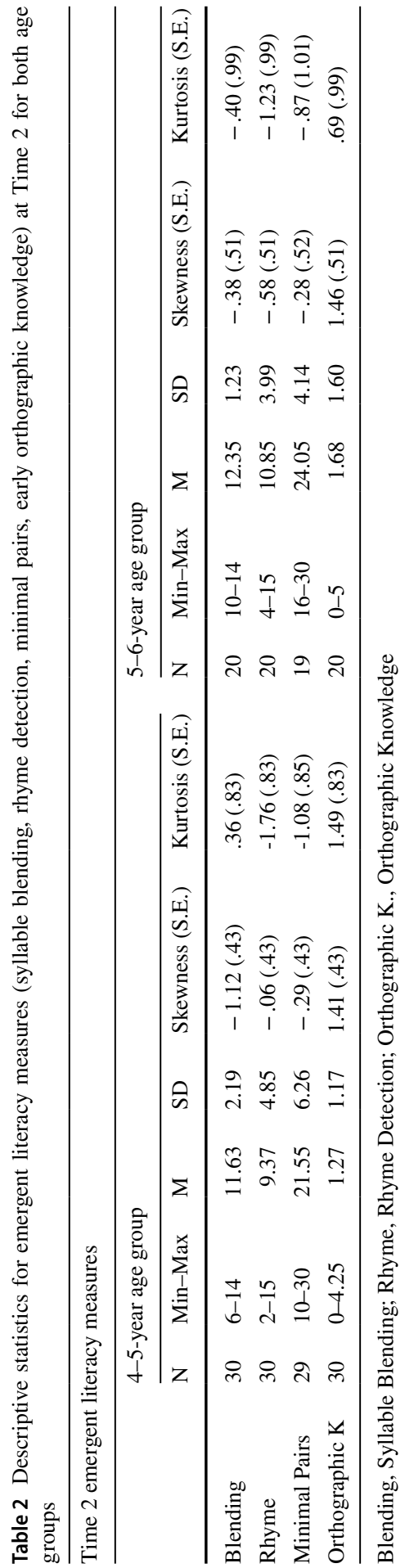




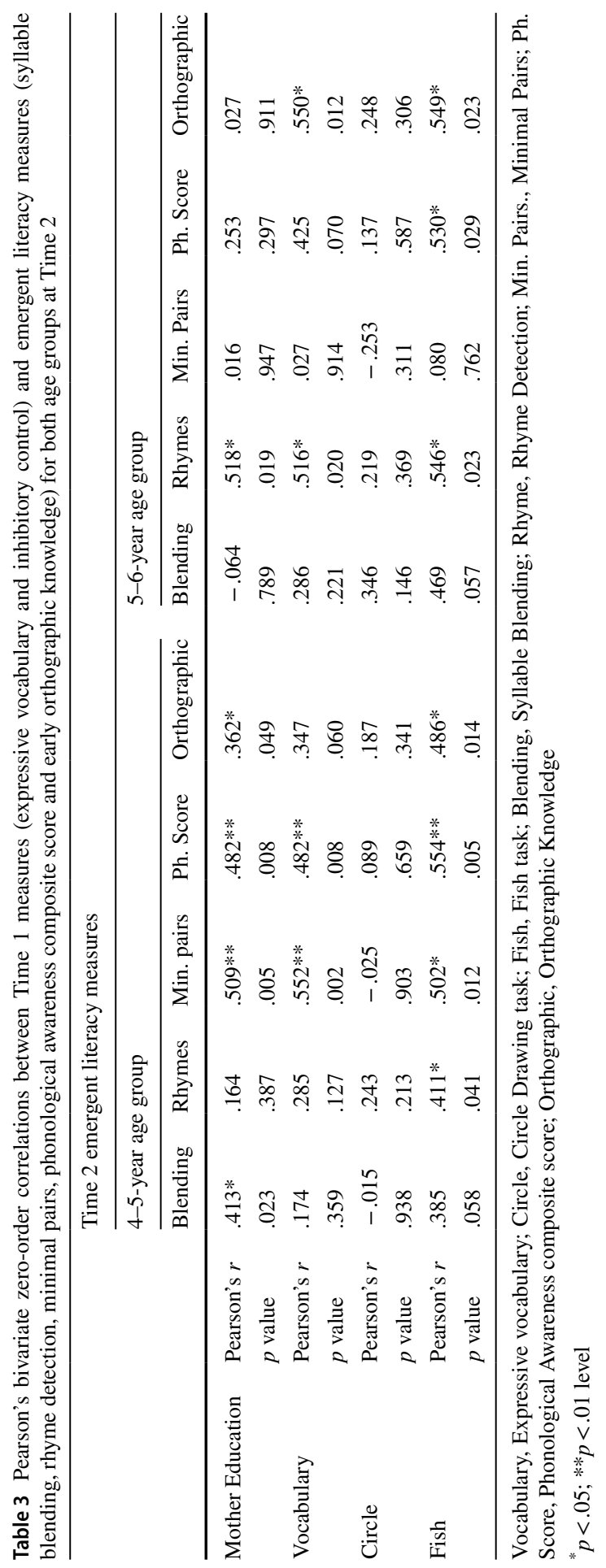


included in the second block, expressive vocabulary and both the inhibitory control measures (the Circle Drawing and the Fish tasks) evaluated at Time 1 were included in the third and in the fourth block, respectively, in order to determine whether they accounted for any additional amount of variance in the model. Time 2 age group was included as a categorical (dummy) variable, where the value of 0 was assigned to the 4-5 year subsample and the value of 1 was assigned to the 5-6 year subsample. Emergent literacy measures (phonological awareness score and early orthographic knowledge measure) were included as dependent variables in separate regression models (Table 4).

The results showed that both regression models were significant and accounted for $37 \%$ of variance in the phonological awareness score and for $24 \%$ of variance in early orthographic knowledge. As regards to the phonological awareness composite score, mother's education (block 2) and Time 1 variables (expressive vocabulary-block 3 -, and both inhibitory control measures,--block 4-) accounted for the additional amount of variance of $19 \%, 15 \%$ and $7 \%$, respectively. The significant predictors of the full model were Time 2 age group, mother's education and the interference suppression measure (the Fish task). Expressive vocabulary evaluated

Table 4 Hierarchical multiple linear regression analyses with Time 2 age group, mother's education, expressive vocabulary and inhibitory control measures at Time 1 predicting emergent literacy measures (phonological awareness composite score and early orthographic knowledge measure) at Time 2

\begin{tabular}{|c|c|c|c|c|c|c|c|c|}
\hline & Phonol & al awe & & & Orthe & phic kr & ledge & \\
\hline & $F(5 ; 40$ & $63, p$ & & & $F(5 ; 4$ & 3.57, & 010 & \\
\hline & $\overline{R^{2}=.4}$ & $a d j=$ & & & $\overline{R^{2}}=$ & $R^{2} a d j$ & & \\
\hline & $\begin{array}{l}R^{2} \Delta= \\
p=.14\end{array}$ & $o=$. & $5, p$ & .07 , & $\begin{array}{l}R^{2} \Delta= \\
.11, p\end{array}$ & $\begin{array}{l}p=.2 \\
58\end{array}$ & 5, & \\
\hline Block 1 & $B$ & $S E$ & Beta & $p$ & $B$ & $S E$ & Beta & $p$ \\
\hline Time 2 age group & .322 & .239 & .211 & .185 & .493 & .449 & .171 & .279 \\
\hline Block 2 & $B$ & $S E$ & Beta & $p$ & $B$ & $S E$ & Beta & $p$ \\
\hline Time 2 age group & .513 & .226 & .337 & .029 & .624 & .465 & .216 & .187 \\
\hline Mother Education & .098 & .032 & .448 & .005 & .072 & .067 & .174 & .287 \\
\hline Block 1-2-3 & $B$ & $S E$ & Beta & $p$ & $B$ & $S E$ & Beta & $p$ \\
\hline Time 2 age group & .560 & .206 & .367 & .010 & .748 & .748 & .259 & .091 \\
\hline Mother Education & .088 & .029 & .402 & .005 & .057 & .058 & .138 & .360 \\
\hline Vocabulary & .011 & .004 & .392 & .005 & .022 & .008 & .404 & .008 \\
\hline Block 1-2-3-4 & $B$ & $S E$ & Beta & $p$ & $B$ & $S E$ & Beta & $p$ \\
\hline Time 2 age group & .484 & .204 & .318 & .023 & .539 & .418 & .187 & .206 \\
\hline Mother Education & .074 & .029 & .337 & .018 & .024 & .060 & .058 & .693 \\
\hline Vocabulary & .008 & .004 & .256 & .092 & .011 & .009 & .205 & .208 \\
\hline Circle & -.140 & .373 & -.052 & .709 & .341 & .771 & .066 & 661 \\
\hline Fish & .139 & .068 & .317 & .049 & .312 & .141 & .373 & .033 \\
\hline
\end{tabular}

Vocabulary, Expressive vocabulary; Circle, Circle Drawing task; Fish, Fish task. Time 2 age group was included as a dummy variable 
at Time 1 was also a significant predictor in block 3 analysis, however, when inhibitory control measures were added to the model, it was no longer significant.

Regarding the early orthographic knowledge measure, the results showed that expressive vocabulary evaluated at Time 1 accounted for a significant amount of variance (16\%), Time 1 inhibitory control measures accounted for an amount of variance of $11 \%$ but this addition was not statistically significant. The interference suppression task was the only significant predictor of the full model. Expressive vocabulary was a significant predictor only in block 3 of the analysis; contrary to the phonological awareness outcome, the results showed that Time 2 age group and mother's education were not significant predictors in the early orthographic knowledge measure.

\section{Discussion}

Phonological awareness and early orthographic knowledge are two important predictors of reading and writing in primary school (Ziegler et al., 2010). Despite the importance of these skills to literacy, relatively little is known about their antecedents (Filipe, Castro, \& Limpo, 2020). This study analyzed whether the development of predictors of emergent literacy is associated with early measures of vocabulary and inhibitory control evaluated in toddlerhood, and suggests that interference suppression is a key process in the acquisition and construction of both phonological awareness and early orthographic knowledge.

These results are in line with prior research demonstrating that self-regulatory processes are strong correlates of early academic skills (e.g., Fuhs, Farran, \& Nesbitt, 2015). In particular, inhibitory control processes are the earliest forms of cognitive control (Diamond, 2013) that significantly contribute to self-regulation (Rueda, Posner, \& Rothbart, 2005) which in turn promotes school readiness and learning skills (McClelland \& Cameron, 2012; Vitiello \& Greenfield, 2017). Unlike previous studies, the present one included very young children, thus allowing us to explore whether emerging forms of inhibitory control in toddlerhood can be predictive of early learning skills that emerge much later, after two or three years. Furthermore, the current study differentiated between two forms of inhibitory control (i.e., response inhibition and interference suppression), in order to identify which specific dimension of inhibition is more closely associated to early literacy. To the best of our knowledge, the differential role of early inhibitory control processes was not longitudinally studied in relation to later literacy achievement.

We first analyzed the association between language and inhibitory control in toddlerhood (Time 1) and the results showed a pattern of significant associations between expressive vocabulary and both inhibitory control measures. It should be noted that both inhibitory measures were non-verbal. Particularly, the interference suppression task (and not the response inhibition one) significantly correlated with expressive vocabulary even when age was partialled out, confirming previous evidence which showed that early oral language skills are associated with inhibitory control in general (Usai, Viterbori, Gandolfi, \& Zanobini, 2020), 
and with the interference suppression component in particular (Gandolfi \& Viterbori, 2020). Considering correlational patterns between language and inhibitory control at Time 1 and emergent literacy measures evaluated at Time 2, the results showed significant associations between expressive vocabulary and phonological awareness at 4-5 years and between expressive vocabulary and early orthographic knowledge at 5-6 years. Interestingly, among the variables considered at Time 1, only interference suppression was found to be associated with phonological awareness and early orthographic knowledge in both age groups. This result suggests that the ability to manage the conflict among misleading features of a task may sustain different and later achievements, such as phonological awareness (Lonigan et al., 2017; Purpura et al., 2017) and early orthographic knowledge skills (Kegel \& Bus, 2014) even after two or three years.

The regression analyses confirmed these correlational patterns. The main findings showed that interference suppression was longitudinally associated with both phonological awareness and early orthographic knowledge skills, even when age group, maternal education level and expressive vocabulary were simultaneously considered. Although early expressive vocabulary was also a significant predictor for both outcomes, when inhibitory control measures were added to the model, it was no longer significant. It should furthermore be noted that, though age group and maternal education were also significant predictors of phonological awareness score, they did not predict early orthographic knowledge.

The significant role of interference suppression in the development of phonological awareness and early orthographic knowledge can be explained in different ways. One hypothesis is that interference suppression is directly involved in tasks assessing phonological awareness and in early orthographic knowledge especially when these skills are not yet automatized. For example, when retrieving the shape of a letter while writing, a child is required to manage the possible interference given by letters with similar shapes (e.g., E and F). A similar interference can be present at a phonological level, for example in a meta-phonological task, when it is important to pay attention only to the sound of the word and ignore other interfering features, such as its meaning. In other words, interference suppression would assist children to select the right piece of information in the presence of interfering stimuli, especially when skills are emerging.

The second hypothesis is that children with higher scores in interference suppression benefit more from educational activities and are generally more ready to learn. For example, when provided with appropriate instruction, a child with better interference suppression may be more able to listen to the instruction and remain on task by filtering interfering and extraneous information. In addition, it was suggested that both inhibitory control processes are related to metacognitive skills in preschoolers and that interference suppression in particular might contribute to metacognitive monitoring by preventing children from being distracted by environmental factors while they update their representations (Bryce, Whitebread, \& Szúcs, 2015). Metacognitive skills in turn positively influence learning outcomes, suggesting there is a chain of relationships from inhibitory control processes and metacognitive skills to achievement. This second hypothesis concerning the relationship between interference suppression and literacy is less specific 
than the first one and in line with research that emphasizes the role of self-regulatory skills in school readiness and attainment (e.g., Blair \& Raver, 2015).

Finally, interference suppression might be related to emergent literacy via oral language skills. Recent research suggests that interference suppression is associated with oral language skills in young children, particularly with early vocabulary and early grammar (Bohlmann, Maier, \& Palacios, 2015; Gandolfi \& Viterbori, 2020). For example, in lexical development, interference suppression skills could help children to check the progressive acquisition of new words and the subsequent increase of possible interference from lexical competitors (Gandolfi \& Viterbori, 2020). Therefore, interference suppression could have a role in the acquisition of lexical skills that in turn are related to early literacy (Cooper, Roth, Speece, \& Schatschneider, 2002; Snowling, Gallagher, \& Frith, 2003). For example, the Lexical Restructuring Model suggests that vocabulary growth in preschool children drives the restructuring of phonological representations, thus promoting phonological awareness (Carroll, Snowling, Hulme, \& Stevenson, 2003; Lonigan, 2007). In fact, when children increase their lexicon, words must be represented more segmentally enabling to differentiate among very similar phonemes of the words, laying the foundation for later phonological awareness skills. In this case, interference suppression, which was found to be associated with oral language abilities, particularly expressive vocabulary, could have a significant indirect role in enhancing early literacy skills.

This study presents some limitations which should be considered for further research. First, the sample size was limited and, as a consequence, in the main regression analyses we could not consider both age groups at Time 2 separately. As a consequence, we could not explore whether the response inhibition measure was involved in emergent literacy at least in the younger age group. In fact, this inhibitory control component was found to be associated with language abilities in very young children (Cozzani, Usai, \& Zanobini, 2013; Gandolfi \& Viterbori, 2020; Viterbori, Gandolfi, \& Usai, 2012). It would have been more appropriate to investigate the predictive role of vocabulary and inhibitory control on early literacy in the 4-5 age group and, separately, in the 5-6 age group, in order to explore which predictor may affect the outcomes after two or three years. However, to reduce this limitation we included the Time 2 age group between the two subsamples as a dummy variable in the regression models.

Second, we chose two inhibitory control tasks to maximize the difference between response inhibition and interference suppression processes, taking the suitability of the task for toddlers into account (see Usai et al., 2017). Since the Circle Drawing task assesses inhibitory control (response inhibition component) by involving the ability to control a motor response and the Fish task assess inhibitory control (interference suppression component) by involving visual attention skills, it might be interesting for further research to select inhibitory measures that involve similar non-executive skills. This would make the measures more comparable in investigating their contribution to the outcomes. With respect to inhibitory control measures, another limitation comes from the relatively low reliability of the Fish task. Nevertheless, it should be considered that the reliability of the inhibitory control tasks is frequently low especially in young children (see also Wiebe et al., 2011, Willoughby 
et al., 2011). Finally, early expressive vocabulary was assessed exclusively with a parent report questionnaire. A concurrent direct examination of lexical skills would have provided a more solid measure. Nevertheless, the MacArthur-Bates Communicative Development Inventory is a widely used questionnaire with adequate psychometric proprieties (Law \& Roy, 2008) that it is particularly suitable in providing representative picture of very young children's language skills in different contexts and situations (Rinaldi, Pasqualetti, Stefanini, Bello, \& Caselli, 2019).

In conclusion, the current study has explored the role of inhibitory control skills evaluated in toddlerhood in some important emergent literacy abilities tested two to three years later. The main finding reveals that interference suppression is the key component that is longitudinally associated with both phonological awareness and early orthographic knowledge, even when early linguistic ability is concurrently considered.

Our findings provide significant theoretical implications because, even though the study wasn't aimed to investigate the latent organization of inhibitory control, it suggests that different inhibitory processes are available even at early ages (see Gandolfi \& Viterbori, 2020). Moreover, these results represent an opportunity to expand the still limited literature on the predictive role that different early inhibitory control abilities could have in explaining emerging literacy skills. Our findings present also some practical implications, providing insights that may help to develop more appropriate educational strategies in support of early inhibitory control skills feasible in early toddlerhood.

Funding Open Access funding provided by Università degli Studi di Genova.

Open Access This article is licensed under a Creative Commons Attribution 4.0 International License, which permits use, sharing, adaptation, distribution and reproduction in any medium or format, as long as you give appropriate credit to the original author(s) and the source, provide a link to the Creative Commons licence, and indicate if changes were made. The images or other third party material in this article are included in the article's Creative Commons licence, unless indicated otherwise in a credit line to the material. If material is not included in the article's Creative Commons licence and your intended use is not permitted by statutory regulation or exceeds the permitted use, you will need to obtain permission directly from the copyright holder. To view a copy of this licence, visit http://creativecommons.org/licen ses/by/4.0/.

\section{References}

Allan, N. P., \& Lonigan, C. J. (2011). Examining the dimensionality of effortful control in preschool children and its relation to academic and socioemotional indicators. Developmental Psychology, 47, 905-915. https://doi.org/10.1037/a0023748.

Araújo, S., Reis, A., Petersson, K. M., \& Faísca, L. (2015). Rapid automatized naming and reading performance: A meta-analysis. Journal of Educational Psychology, 107, 868-883. https://doi. org/10.1037/edu0000006.

Becker, D. R., Miao, A., Duncan, R., \& McClelland, M. M. (2014). Behavioral self-regulation and executive function both predict visuomotor skills and early academic achievement. Early Childhood Research Quarterly, 29, 411-424. https://doi.org/10.1016/j.ecresq.2014.04.014.

Bello, A., Giannantoni, P., Pettenati, P., Stefanini, S., \& Caselli, M. C. (2012). Assessing lexicon: Validation and developmental data of the Picture Naming Game (PiNG), a new picture naming task for 
toddlers. International Journal of Language \& Communication Disorders, 47, 589-602. https:// doi.org/10.1111/j.1460-6984.2012.00168.x.

Binamé, F., \& Poncelet, M. (2016). Order short-term memory capacity predicts nonword reading and spelling in first and second grade. Reading and Writing, 29, 1-20. https://doi.org/10.1007/s1114 5-015-9577-9.

Blair, C., \& Raver, C. C. (2015). School readiness and self-regulation: A developmental psychobiological approach. Annual Review of Psychology, 66, 711-731. https://doi.org/10.1146/annurev-psych -010814-015221.

Bohlmann, N. L., Maier, M. F., \& Palacios, N. (2015). Bidirectionality in self-regulation and expressive vocabulary: Comparisons between monolingual and dual language learners in preschool. Child Development, 86, 1094-1111. https://doi.org/10.1111/cdev.12375.

Bossert, M., Kaurin, A., Preckel, F., \& Frings, C. (2014). Response-compatibility effects in children. European Journal of Developmental Psychology, 11, 90-101. https://doi.org/10.1080/17405 629.2013.819286.

Bryce, D., Whitebread, D., \& Szúcs, D. (2015). The relationships among executive functions, metacognitive skills and educational achievement in 5 and 7 year-old children. Metacognition and Learning, 10, 181-198. https://doi.org/10.1007/s11409-014-9120-4.

Bunge, S. A., Dudukovic, N. M., Thomason, M. E., Vaidya, C. J., \& Gabrieli, J. D. (2002). Immature frontal lobe contributions to cognitive control in children: Evidence from fMRI. Neuron, 33, 301311. https://doi.org/10.1016/S0896-6273(01)00583-9.

Caravolas, M., Hulme, C., \& Snowling, M. J. (2001). The foundations of spelling ability: Evidence from a 3-year longitudinal study. Journal of Memory and Language, 45, 751-774. https://doi.org/10.1006/ jmla.2000.2785.

Carlson, S. M., \& Moses, L. J. (2001). Individual differences in inhibitory control and children's theory of mind. Child Development, 72, 1032-1053. https://doi.org/10.1111/1467-8624.00333.

Carroll, J. M., Snowling, M. J., Stevenson, J., \& Hulme, C. (2003). The development of phonological awareness in preschool children. Developmental Psychology, 39, 913-923. https://doi. org/10.1037/0012-1649.39.5.913.

Caselli, M. C., Pasqualetti, P., \& Stefanini, S. (2007). Parole e frasi nel "Primo Vocabolario del Bambino”: Nuovi dati normativi fra 18 e 36 mesi e Forma breve del questionario. Milan, Italy: Franco Angeli.

Castles, A., \& Coltheart, M. (2004). Is there a causal link from phonological awareness to success in learning to read? Cognition, 91, 77-111. https://doi.org/10.1016/S0010-0277(03)00164-1.

Castles, A., \& Nation, K. (2006). How does orthographic learning happen? In S. Andrews (Ed.), From inkmarks to ideas: Current issues on lexical processing (pp. 151-179). New York, NY: Psychology Press.

Conrad, N. J., Harris, N., \& Williams, J. (2013). Individual differences in children's literacy development: The contribution of orthographic knowledge. Reading and Writing, 26, 1223-1239. https:// doi.org/10.1007/s11145-012-9415-2.

Cooper, D. H., Roth, F. P., Speece, D. L., \& Schatschneider, C. (2002). The contribution of oral language skills to the development of phonological awareness. Applied Psycholinguistics, 23, 399-416. https ://doi.org/10.1017/S0142716402003053.

Cozzani, F., Usai, M. C., \& Zanobini, M. (2013). Linguistic abilities and executive function in the third year of life. Rivista Italiana di Psicolinguistica applicata/Journal of applied psycholinguistics, 13, $25-43$.

Curtin, S., \& Zamuner, T. S. (2014). Understanding the developing sound system: Interactions between sounds and words. Wiley Interdisciplinary Reviews: Cognitive Science, 5, 589-602. https://doi. org/10.1002/wcs.1307.

De Jong, P. F., \& Van der Leij, A. (1999). Specific contributions of phonological abilities to early reading acquisition: Results from a Dutch latent variable longitudinal study. Journal of Educational Psychology, 91, 450-476. https://doi.org/10.1037/0022-0663.91.3.450.

Diamond, A. (2013). Executive functions. Annual Review of Psychology, 64, 135-168. https://doi. org/10.1146/annurev-psych-113011-143750.

Diamond, A., Prevor, M. B., Callender, G., \& Druin, D. P. (1997). Prefrontal cortex cognitive deficits in children treated early and continuously for PKU. Monographs of the Society for Research in Child Development. https://doi.org/10.2307/1166208.

Dickinson, D. K., McCabe, A., Anastasopoulos, L., Peisner-Feinberg, E. S., \& Poe, M. D. (2003). The comprehensive language approach to early literacy: The interrelationships among vocabulary, 
phonological sensitivity, and print knowledge among preschool-aged children. Journal of Educational Psychology, 95, 465-481. https://doi.org/10.1037/0022-0663.95.3.465.

Eriksen, B. A., \& Eriksen, C. W. (1974). Effects of noise letters upon the identification of a target letter in a nonsearch task. Perception and Psychophysics, 16, 143-149. https://doi.org/10.3758/BF032 03267.

Fasolo, M., Majorano, M., \& D’Odorico, L. (2008). Babbling and first words in children with slow expressive development. Clinical Linguistics \& Phonetics, 22, 83-94. https://doi.org/10.1080/02699 200701600015.

Fenson, L., Dale, P. S., Reznick, J. S., Thal, D., Bates, E., Hartung, J. P., et al. (1993). The MacArthur Communicative Development Inventory: Words and Sentences. San Diego, CA: Singular.

Fenson, L., Marchman, V. A., Thal, D. J., Dale, P. S., \& Reznick, J. S. (2007). MacArthur-bates communicative development inventories. Baltimore, $\mathrm{MD}$ : Paul $\mathrm{H}$.

Ferreiro, E., \& Teberosky, A. (1982). Literacy Before Schooling. New Hampshire, UK: Heineman.

Filipe, M., Castro, S. L., \& Limpo, T. (2020). The link between executive functions and literacy: Introduction. Reading and Writing, 33, 807-812. https://doi.org/10.1007/s11145-020-10037-1.

Fuhs, M. W., \& McNeil, N. M. (2013). ANS acuity and mathematics ability in preschoolers from lowincome homes: Contributions of inhibitory control. Developmental Science, 16, 136-148. https ://doi.org/10.1111/desc.12013.

Fuhs, M. W., Farran, D. C., \& Nesbitt, K. T. (2015). Prekindergarten children's executive functioning skills and achievement gains: The utility of direct assessments and teacher ratings. Journal of Educational Psychology, 107, 207-221. https://doi.org/10.1037/a0037366.

Friedman, N. P., \& Miyake, A. (2004). The relations among inhibition and interference control functions: A latent-variable analysis. Journal of Experimental Psychology: General, 133, 101-135. https://doi.org/10.1037/0096-3445.133.1.101.

Gandolfi, E., \& Viterbori, P. (2020). Inhibitory control skills and language acquisition in toddlers and preschool children. Language Learning, 70, 604-642. https://doi.org/10.1111/lang.12388.

Gandolfi, E., Viterbori, P., Traverso, L., \& Usai, M. C. (2014). Inhibitory processes in toddlers: A latent-variable approach. Frontiers in Psychology, 5, 381. https://doi.org/10.3389/fpsyg .2014.00381.

Goswami, U. (1999). Phonological development and reading by analogy: Epilinguistic and metalinguistic issues. In J. Oakhill \& R. Beard (Eds.), Reading development and the teaching of reading: A psychological perspective (pp. 174-200). Hoboken: Blackwell Science.

Goswami, U. (2000). Phonological representations, reading development and dyslexia: Towards a cross-linguistic theoretical framework. Dyslexia, 6, 133-151. https://doi.org/10.1002/ (SICI)1099-0909(200004/06)6:2\%3C133::AID-DYS160\%3E3.0.CO;2-A.

Goswami, U., \& Bryant, P. (2016). Phonological skills and learning to read. London: Psychology Press. https://doi.org/10.4324/9781315785110.

Geurts, H. M., Verté, S., Oosterlaan, J., Roeyers, H., \& Sergeant, J. A. (2005). ADHD subtypes: do they differ in their executive functioning profile? Archives of Clinical Neuropsychology, 20, 457-477. https://doi.org/10.1016/j.acn.2004.11.001.

Hooper, S. R., Costa, L. C., Green, M. B., Catlett, S. R., Barker, A., Fernandez, E., \& Faldowski, R. A. (2020). The relationship of teacher ratings of executive functions to emergent literacy in Head Start. Reading and Writing, 33, 963-989. https://doi.org/10.1007/s11145-019-09992-1.

Hughes, C., Ensor, R., Wilson, A., \& Graham, A. (2009). Tracking executive function across the transition to school: A latent variable approach. Developmental Neuropsychology, 35, 20-36. https ://doi.org/10.1080/87565640903325691.

Joyce, A. W., Kraybill, J. H., Chen, N., Cuevas, K., Deater-Deckard, K., \& Bell, M. A. (2016). A longitudinal investigation of conflict and delay inhibitory control in toddlers and preschoolers. Early Education and Development, 27, 788-804. https://doi.org/10.1080/10409289.2016.11484 81.

Kegel, C. A., \& Bus, A. G. (2014). Evidence for causal relations between executive functions and alphabetic skills based on longitudinal data. Infant and Child Development, 23, 22-35. https://doi. org/10.1002/icd.1827.

Kim, Y. S., Al Otaiba, S., Puranik, C., Folsom, J. S., \& Gruelich, L. (2014). The contributions of vocabulary and letter writing automaticity to word reading and spelling for kindergartners. Reading and Writing, 27, 237-253. https://doi.org/10.1007/s11145-013-9440-9. 
Kim, Y. S., Al Otaiba, S., Puranik, C., Folsom, J. S., Greulich, L., \& Wagner, R. K. (2011). Componential skills of beginning writing: An exploratory study. Learning and Individual Differences, 21, 517-525. https://doi.org/10.1016/j.lindif.2011.06.004.

Kirby, J. R., Desrochers, A., Roth, L., \& Lai, S. S. (2008). Longitudinal predictors of word reading development. Canadian Psychology/Psychologie Canadienne, 49, 103-110. https://doi. org/10.1037/0708-5591.49.2.103.

Kochanska, G., Murray, K. T., \& Harlan, E. T. (2000). Effortful control in early childhood: Continuity and change, antecedents, and implications for social development. Developmental Psychology, 36, 220-232. https://doi.org/10.1037/0012-1649.36.2.220.

Lee, L. W. (2008). Development and validation of a reading-related assessment battery in Malay for the purpose of dyslexia assessment. Annals of Dyslexia, 58, 37-57. https://doi.org/10.1007/s1188 1-007-0011-0.

Leseman, P. P., \& De Jong, P. F. (1998). Home literacy: Opportunity, instruction, cooperation and socialemotional quality predicting early reading achievement. Reading Research Quarterly, 33, 294-318. https://doi.org/10.1598/RRQ.33.3.3.

Lehto, J. E., Juujärvi, P., Kooistra, L., \& Pulkkinen, L. (2003). Dimensions of executive functioning: Evidence from children. British Journal of Developmental Psychology, 21, 59-80. https://doi. org/10.1348/026151003321164627.

Lonigan, C. J. (2007). Vocabulary development and the development of phonological awareness skills in preschool children. In R. K. Wagner, A. E. Muse, \& K. R. Tannenbaum (Eds.), Vocabulary acquisition: Implications for reading comprehension (pp. 15-31). New York: Guilford.

Lonigan, C. J., Allan, D. M., \& Phillips, B. M. (2017). Examining the predictive relations between two aspects of self-regulation and growth in preschool children's early literacy skills. Developmental Psychology, 53, 63-76. https://doi.org/10.1037/dev0000247.

Lonigan, C. J., Anthony, J. L., Phillips, B. M., Purpura, D. J., Wilson, S. B., \& McQueen, J. D. (2009). The nature of preschool phonological processing abilities and their relations to vocabulary, general cognitive abilities, and print knowledge. Journal of Educational Psychology, 101, 345-358. https:// doi.org/10.1037/a0013837.

Lonigan, C. J., Burgess, S. R., \& Anthony, J. L. (2000). Development of emergent literacy and early reading skills in preschool children: Evidence from a latent-variable longitudinal study. Developmental Psychology, 36, 596-613. https://doi.org/10.1037/0012-1649.36.5.596.

Lonigan, C. J., Lerner, M. D., Goodrich, J. M., Farrington, A. L., \& Allan, D. M. (2016). Executive function of Spanish-speaking language-minority preschoolers: Structure and relations with early literacy skills and behavioral outcomes. Journal of Experimental Child Psychology, 144, 46-65. https://doi.org/10.1016/j.jecp.2015.11.003.

Lonigan, C. J., \& Shanahan, T. (2009). Developing early literacy: Report of the National Early Literacy Panel. Executive summary. A Scientific synthesis of early literacy development and implications for intervention. National Institute for Literacy.

Law, J., \& Roy, P. (2008). Parental report of infant language skills: A review of the development and application of the Communicative Development Inventories. Child and Adolescent Mental Health, 13, 198-206. https://doi.org/10.1111/j.1475-3588.2008.00503.x.

Marotta, L., Trasciani, M., \& Vicari, S. (2008). Test CMF. Valutazione delle competenze metafonologiche. Trento, Italy: Erickson.

Martin-Rhee, M. M., \& Bialystok, E. (2008). The development of two types of inhibitory control in monolingual and bilingual children. Bilingualism, 11, 81-93. https://doi.org/10.1017/S136672890 7003227.

McClelland, M. M., \& Cameron, C. E. (2012). Self-regulation in early childhood: Improving conceptual clarity and developing ecologically valid measures. Child Development Perspectives, 6, 136-142. https://doi.org/10.1111/j.1750-8606.2011.00191.x.

McClelland, M. M., Cameron, C. E., Connor, C. M., Farris, C. L., Jewkes, A. M., \& Morrison, F. J. (2007). Links between behavioral regulation and preschoolers' literacy, vocabulary, and math skills. Developmental Psychology, 43, 947-959. https://doi.org/10.1037/0012-1649.43.4.947.

McClelland, M. M., Cameron, C. E., Duncan, R., Bowles, R. P., Acock, A. C., Miao, A., \& Pratt, M. E. (2014). Predictors of early growth in academic achievement: The head-toes-knees-shoulders task. Frontiers in Psychology, 5, 599. https://doi.org/10.3389/fpsyg.2014.00599.

Metsala, J. L., \& Walley, A. C. (1998). Spoken vocabulary growth and the segmental restructuring of lexical representations: Precursors to phonemic awareness and early reading ability. In J. L. Metsala \& L. C. Ehri (Eds.), Word recognition in beginning literacy (pp. 89-120). Mahwah, NJ: Erlbaum. 
Milburn, T. F., Hipfner-Boucher, K., Weitzman, E., Greenberg, J., Pelletier, J., \& Girolametto, L. (2017). Cognitive, linguistic and print-related predictors of preschool children's word spelling and name writing. Journal of Early Childhood Literacy, 17, 111-136. https://doi.org/10.1177/1468798415 624482.

Miyake, A., \& Friedman, N. P. (2012). The nature and organization of individual differences in executive functions: Four general conclusions. Current Directions in Psychological Science, 21, 8-14. https ://doi.org/10.1177/0963721411429458.

Montoya, M. F., Susperreguy, M. I., Dinarte, L., Morrison, F. J., San Martin, E., Rojas-Barahona, C. A., \& Förster, C. E. (2019). Executive function in Chilean preschool children: Do short-term memory, working memory, and response inhibition contribute differentially to early academic skills? Early Childhood Research Quarterly, 46, 187-200. https://doi.org/10.1016/j.ecresq.2018.02.009.

Otaiba, S. A., Puranik, C. S., Rouby, D. A., Greulich, L., Sidler, J. F., \& Lee, J. (2010). Predicting kindergarteners' end-of-year spelling ability based on their reading, alphabetic, vocabulary, and phonological awareness skills, as well as prior literacy experiences. Learning Disability Quarterly, 33, 171-183. https://doi.org/10.1177/073194871003300306.

Ouellette, G., \& Sénéchal, M. (2008). Pathways to literacy: A study of invented spelling and its role in learning to read. Child Development, 79, 899-913. https://doi.org/10.1111/j.1467-8624.2008.01166.x.

Petersen, I. T., Hoyniak, C. P., McQuillan, M. E., Bates, J. E., \& Staples, A. D. (2016). Measuring the development of inhibitory control: The challenge of heterotypic continuity. Developmental Review, 40, 25-71. https://doi.org/10.1016/j.dr.2016.02.001.

Peterson, R. L., Arnett, A. B., Pennington, B. F., Byrne, B., Samuelsson, S., \& Olson, R. K. (2018). Literacy acquisition influences children's rapid automatized naming. Developmental Science, 21, e12589. https ://doi.org/10.1111/desc.12589.

Plaza, M., \& Cohen, H. (2007). The contribution of phonological awareness and visual attention in early reading and spelling. Dyslexia, 13, 67-76. https://doi.org/10.1002/dys.330.

Poe, M. D., Burchinal, M. R., \& Roberts, J. E. (2004). Early language and the development of children's reading skills. Journal of School Psychology, 42, 315-332. https://doi.org/10.1016/j.jsp.2004.06.001.

Purpura, D. J., Schmitt, S. A., \& Ganley, C. M. (2017). Foundations of mathematics and literacy: The role of executive functioning components. Journal of Experimental Child Psychology, 153, 15-34. https://doi. org/10.1016/j.jecp.2016.08.010.

Rinaldi, P., Pasqualetti, P., Stefanini, S., Bello, A., \& Caselli, M. C. (2019). The Italian Words and Sentences MB-CDI: Normative data and concordance between complete and short forms. Journal of Child Language, 46, 546-566. https://doi.org/10.1017/S0305000919000011.

Ring, E. D., \& Fenson, L. (2000). The correspondence between parent report and child performance for receptive and expressive vocabulary beyond infancy. First Language, 20, 141-159. https://doi. org/10.1177/014272370002005902.

Rueda, M. R., Posner, M. I., \& Rothbart, M. K. (2005). The development of executive attention: Contributions to the emergence of self-regulation. Developmental Neuropsychology, 28, 573-594. https://doi. org/10.1207/s15326942dn2802_2.

Schuele, C. M., \& Boudreau, D. (2008). Phonological awareness intervention: Beyond the basics. Language, Speech, and Hearing Services in Schools, 39, 3-20. https://doi.org/10.1044/0161-1461(2008/002).

Shaul, S., \& Schwartz, M. (2014). The role of the executive functions in school readiness among preschoolage children. Reading and Writing, 27, 749-768. https://doi.org/10.1007/s11145-013-9470-3.

Snowling, M. J., Gallagher, A., \& Frith, U. (2003). Family risk of dyslexia is continuous: Individual differences in the precursors of reading skill. Child Development, 74, 358-373. https://doi. org/10.1111/1467-8624.7402003.

Sosa, A. V., \& Stoel-Gammon, C. (2012). Lexical and phonological effects in early word production. Journal of Speech, Language, and Hearing Research, 55, 596-608. https://doi. org/10.1044/1092-4388(2011/10-0113).

Storkel, H. L., \& Morrisette, M. L. (2002). The lexicon and phonology. Language, Speech, and Hearing Services in Schools, 33, 24-37. https://doi.org/10.1044/0161-1461(2002/003).

Suggate, S., Schaughency, E., McAnally, H., \& Reese, E. (2018). From infancy to adolescence: The longitudinal links between vocabulary, early literacy skills, oral narrative, and reading comprehension. Cognitive Development, 47, 82-95. https://doi.org/10.1016/j.cogdev.2018.04.005.

Traverso, L., Fontana, M., Usai, M. C., \& Passolunghi, M. C. (2018). Response inhibition and interference suppression in individuals with down syndrome compared to typically developing children. Frontiers in Psychology, 9, 660. https://doi.org/10.3389/fpsyg.2018.00660. 
Traverso, L., Mantini, C., Usai, M. C., \& Viterbori, P. (2016). Valutare le capacità di regolazione in età prescolare: il preschool matching familiar figure task. Psicologia clinica dello sviluppo, 20, 189-210. https://doi.org/10.1449/84130.

Traverso, L., Viterbori, P., Malagoli, C., \& Usai, M. C. (2020). Distinct inhibition dimensions differentially account for working memory performance in 5-year-old children. Cognitive Development, 55, 100909. https://doi.org/10.1016/j.cogdev.2020.100909.

Traverso, L., Viterbori, P., \& Usai, M. C. (2019). Effectiveness of an executive function training in Italian preschool educational services and far transfer effects to pre-academic skills. Frontiers in Psychology, 10, 2053. https://doi.org/10.3389/fpsyg.2019.02053.

Traverso, L., Viterbori, P., \& Usai, M. C. (2015). Improving executive function in childhood: Evaluation of a training intervention for 5-year-old children. Frontiers in Psychology, 6, 525. https://doi.org/10.3389/ fpsyg.2015.00525.

Usai, M. C., Traverso, L., Gandolfi, E., \& Viterbori, P. (2017). Batteria per la valutazione delle funzioni esecutive in età Prescolare. Trento, Italy: Erickson.

Usai, M. C., Viterbori, P., Gandolfi, E., \& Zanobini, M. (2020). The relationship between temperamental dimensions and inhibitory control in early childhood: Implications for language acquisition. Infant Behavior and Development, 61. https://doi.org/10.1016/j.infbeh.2020.101495.

Usai, M. C., Viterbori, P., Traverso, L., \& De Franchis, V. (2014). Latent structure of executive function in five-and six-year-old children: A longitudinal study. European Journal of Developmental Psychology, 11, 447-462. https://doi.org/10.1080/17405629.2013.840578.

Viterbori, P., Gandolfi, E., \& Usai, M. C. (2012). Executive skills and early language development. Rivista Italiana di Psicolinguistica applicata/Journal of applied psycholinguistics, 3, 17-32.

Viterbori, P., Zanobini, M., \& Cozzani, F. (2018). Phonological development in children with different lexical skills. First Language, 38, 538-559. https://doi.org/10.1177/0142723718784369.

Vitiello, V. E., \& Greenfield, D. B. (2017). Executive functions and approaches to learning in predicting school readiness. Journal of Applied Developmental Psychology, 53, 1-9. https://doi.org/10.1016/j. appdev.2017.08.004.

Wagner, R. K., Torgesen, J. K., Rashotte, C. A., \& Pearson, N. A. (1999). Comprehensive test of phonological processing: CTOPP. Austin, TX: Pro-ed.

Walley, A. C., Metsala, J. L., \& Garlock, V. M. (2003). Spoken vocabulary growth: Its role in the development of phoneme awareness and early reading ability. Reading and Writing, 16, 5-20. https://doi. org/10.1023/A:1021789804977.

Wiebe, S., Sheffield, T., Nelson, J. M., Clark, C. A. C., Chevalier, N., \& Espy, K. (2011). The structure of executive function in 3-year-olds. Journal of Experimental Child Psychology, 108, 436-452. https:// doi.org/10.1016/j.jecp.2010.08.008.

Whitehurst, G. J., \& Lonigan, C. J. (2001). Emergent literacy: Development from pre-readers to readers. In S. B. Neuman \& D. K. Dickinson (Eds.), Handbook of early literacy research (pp. 11-29). New York: Guilford Press.

Willoughby, M., Kupersmidt, J., Voegler-Lee, M., \& Bryant, D. (2011). Contributions of hot and cool selfregulation to preschool disruptive behavior and academic achievement. Developmental Neuropsychology, 36, 162-180. https://doi.org/10.1080/87565641.2010.549980.

Wolf, M., \& Bowers, P. G. (1999). The double-deficit hypothesis for the developmental dyslexias. Journal of Educational Psychology, 91, 415-438. https://doi.org/10.1037/0022-0663.91.3.415.

Zanobini, M., Viterbori, P., \& Saraceno, F. (2012). Phonology and language development in Italian children: An analysis of production and accuracy. Journal of Speech, Language, and Hearing Research, 55, 16-31. https://doi.org/10.1044/1092-4388(2011/10-0228).

Zhang, C., Bingham, G. E., \& Quinn, M. F. (2017). The associations among preschool children's growth in early reading, executive function, and invented spelling skills. Reading and Writing, 30, 1705-1728. https://doi.org/10.1007/s11145-017-9746-0.

Ziegler, J. C., Bertrand, D., Tóth, D., Csépe, V., Reis, A., Faísca, L., et al. (2010). Orthographic depth and its impact on universal predictors of reading: A cross-language investigation. Psychological Science, 21, 551-559. https://doi.org/10.1177/0956797610363406.

Publisher's Note Springer Nature remains neutral with regard to jurisdictional claims in published maps and institutional affiliations. 